INNOVATIONS IN PRIMARY CARE

\title{
The Implementation of a Clinic-Based Opioid Review Board to Address High-Risk Opioid Prescribing in Primary Care
}

\author{
Jonatban L. Robbins, MD \\ Afaf Sharen Azar, MD \\ Julie Byler, DO \\ Angela Vinti, PharmD \\ P. Todd Korthuis, MD, MPH \\ Scott Watson, MSW
}

Ann Fam Med 2021;19:563. https://doi.org/10.1370/afm.2738.

\section{INNOVATION}

The 2016 Centers for Disease Control and Prevention (CDC) Guideline for Prescribing Opioids for Chronic Pain emphasized safety risks of opioids while promoting a risk-benefit approach to opioid prescribing. ${ }^{1}$ Although the CDC focused on prescriber decision making around opioid therapy, primary care practices have had little guidance on structural methods that can support safer prescribing. ${ }^{2}$ We created a clinic-based interprofessional opioid review board (ORB) as a low-barrier, low-cost intervention to improve opioid prescribing safety.

\section{WHO \& WHERE}

The Internal Medicine clinic at Oregon Health $\&$ Science University is a large urban adult primary care practice staffed by 33 faculty physicians and 38 internal medicine residents. We formed an ORB which includes several faculty physicians, a clinical pharmacist, a licensed clinical social worker, a medical assistant, a patient access specialist, and a medical resident. In February 2017, at the inception of the ORB quality intervention, there were 664 patients (5.2\% of total practice) on chronic opioid therapy (COT) (Supplemental Appendix, https://www.Ann FamMed.org/lookup/suppl/doi:10.1370/afm.2738/-/DC1).

\section{HOW}

Our clinic's ORB convenes monthly for 1 hour and has several functions: (1) to set clinic policy for safe opioid prescribing aligned with state and federal guidelines and evidence-based

Conflicts of interest: authors report none.

\section{Corresponding author}

Jonathan Robbins

Division of General Internal Medicine \& Geriatrics, School of Medicine Oregon Health \& Science University

Mail Code: L-475

3181 SW Sam Jackson Park Rd

Portland, OR 97239

robbijon@ohsu.edu practices; (2) to update the patient-clinician opioid agreement; and (3) to conduct formal case reviews of 2 to 4 patients monthly. We will focus on the process of case reviews.

Patients with 6 opioid prescriptions within the most recent 9 months or who have an active opioid agreement make up an electronic registry of patients with COT. From this registry, review board leaders identify cases with high morphine equivalent daily dose (MEDD) or benzodiazepine co-prescribing. We invite the prescribing physician to attend the ORB meeting to provide perspective. The interactions between the ORB and prescribers have remained collegial and constructive.

Two physicians from the committee independently review each case before the ORB meeting. Reviewers make note of pain history, taper attempts, prescription drug-monitoring program data, urine drug screens, visits and cancellation history, opioid-related side effects, alcohol and drug history, active medications, and documentation of functional benefit. A subset of patients have had adverse response to tapering; for these patients, documentation of secondary review supporting the treatment plan is entered in the chart. For patients not in this exceptional group, review findings are summarized in the chart along with specific recommendations to the physician (Supplemental Appendix). A committee follow-up plan is included. Typical recommendations include explicit guidance for opioid or benzodiazepine taper, or to transition to sublingual buprenorphine, ${ }^{3}$ with or without referral to behavioral health, a clinical pharmacist, or substance use disorder treatment.

\section{LEARNING}

The ORB has improved clinic alignment with state and federal guidelines. Collaboration with the prescribing physicians has created a supportive, non-adversarial process in which clinicians do not feel chastised. Increasingly, physicians actively solicit the ORB for assistance in difficult cases, such as high MEDD, aberrant behavior, or concern for substance use disorder. We have observed a consistent decline in high-MEDD prescribing in our practice and increasing use of buprenorphine since implementation of this review board (Supplemental Appendix).

For supplemental materials, including affiliations, references, and supplemental appendix, go to https://www.AnnFamMed.orgl lookup/suppl/doi:10.1370/afm.2738I-IDC1.

Key words: opioid review board; opioid tapering; chronic opioid therapy; buprenorphine

Submitted March 18, 2021; accepted April 13, 2021. 